Indexed by

\title{
EXPERIMENTAL STUDY OF THE MECHANICAL
Scopus
EFFECT OF BIO-LOADS ON PVC RECYCLING
}

Crossref

KOBSON

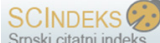

Google

\section{Abdelghani Lakhdar}

SSDIA Laboratory, Hassan II University of Casablanca, ENSET of Mohammedia, 28830, Morocco

\section{Aziz Moumen}

SSDIA Laboratory, Hassan II University of Casablanca, ENSET of Mohammedia, 28830, Morocco

\author{
Khalifa Mansouri \\ SSDIA Laboratory, Hassan \\ II University of \\ Casablanca, ENSET of \\ Mohammedia, 28830, \\ Morocco
}

Key words: flexible and rigid PVC, recycling, coconut, cow-horns, cicken feathers doi:10.5937/jaes0-30892

\section{Cite article:}

Lakhdar A., Moumen A., Moumen K. (2022) EXPERIMENTAL STUDY OF THE MECHANICAL EFFECT OF BIO-LOADS ON PVC RECYCLING, Journal of Applied Engineering Science, 20(1), 221 - 229, DOI:10.5937/ jaes0-30892 


\title{
EXPERIMENTAL STUDY OF THE MECHANICAL EFFECT OF BIO-LOADS ON PVC RECYCLING
}

\author{
Abdelghani Lakhdar*, Aziz Moumen, Khalifa Mansouri \\ SSDIA Laboratory, Hassan II University of Casablanca, ENSET of Mohammedia, 28830, Morocco
}

With the increase in plastic waste, recycling becomes an urgent necessity to reduce and revalue it. PVC is one of the most widely used types of plastic in the world, and indeed it is among the most recycled. The effect of recycling on PVC or any other type of material is to reduce these characteristics, which also depends on the method by which it is recycled.Finding a way to increase the recyclability number of PVC by improving the mechanical characteristics will be an addition at the level of scientific research as well as at the industrial level. The addition of a bio-loading in the form of cow horns, coconut or chicken feathers on the flexible PVC with an experimental study of the results obtained allow to deduce the most adequate bio-loaded material to improve the mechanical characteristics after recycling. The experiments carried out on flexible PVC have shown the effects of bio-loading as well as the degradation brought by recycling on this type of plastic. The results obtained showed an improvement in the mechanical properties of rigid and flexible PVC with a natural bio-loading with the three fibers of coconut, cow horns and chicken feathers which enhance the environment, are very light and can be collected directly from the waste with a large amount.

Key words: flexible and rigid PVC, recycling, coconut, cow-horns, cicken feathers

\section{INTRODUCTION}

Single or in combination with others, plastics are the materials of today and tomorrow. By their lightness, their low cost and their recyclability, they manage to compete with other materials both at the industrial level and at the level of scientific research. Second classified after polyethylene, PVC has become the focus of many industrialists and researchers for the production and recycling of waste. [1] to [4], [11] Scientific research on PVC recycling becomes a glaring necessity by citing the tonnages of waste recycled in the VinylPlus framework during the period from January 1, 2019 to December 31, 2019, by the initiatives of the EuPC sector groups and industry associations and by Recovinyl. [23] The study on PVC recycling begins first with artificial aging simulating the effects of real aging [5] consists of accelerating the degradation of the material using an oven with ultraviolet rays. After validation of the rigid and flexible PVC aging model, comes the treatment of variations and degradations of the mechanical properties brought to the material by recycling. In order to improve the mechanical properties of recycled PVC, the addition of a bio-load was an advantageous solution in terms of cost and availability; they are usually collected and burned with household garbage in landfills. The choice of bio-loads fell on three types: cow horns, coconut and chicken feathers. Each bio-load was washed, dried, crushed and sifted then added with a well-defined percentage to the aged PVC, crushed and also sifted. [15] [24] The study is carried out experimentally with tensile and hardness tests, on bio-load recycled PVC specimens. The tensile tests are carried out on flexible PVC for its simplicity in terms of recycling, while the hardness tests are of course made on rigid $\mathrm{PVC}$.
The experimental results converge on one of the three bio-loads which improves the properties of recycled PVC the most. this bio-load makes it possible to improve flexibility by increasing the elongation at break, and hardness by reducing the stresses at break.

\section{AGING AND RECYCLING OF PVC}

Aging is achieved by exposing rigid PVC to a constant temperature of $328.15 \mathrm{~K}$ and UV (ultraviolet) rays for 15 days of samples and flexible PVC to an irregular temperature of 104 minutes modelling the day then cooling to room temperature for 104 minutes to model the night. The 104 min delay is obtained by an Arduino board which controls a " $5 \mathrm{~V} / 220 \mathrm{~V} / 10 \mathrm{~A}$ " relay.

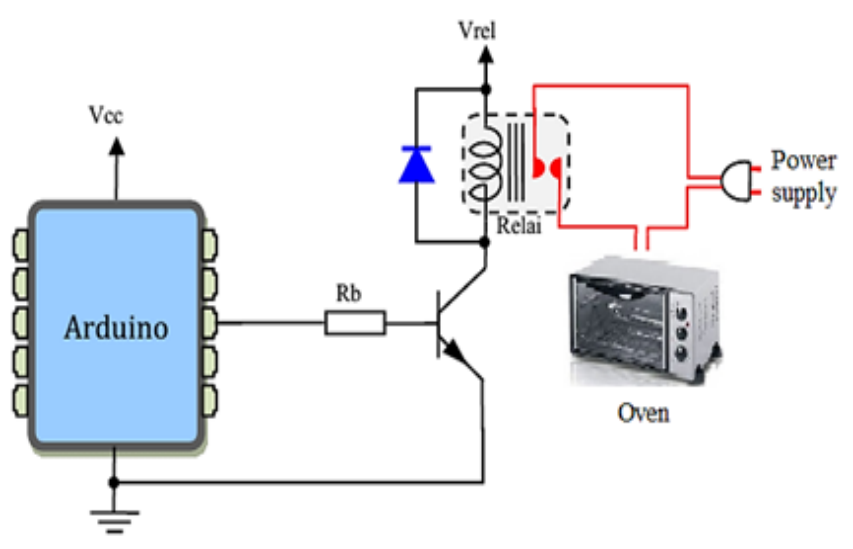

Figure 1: Electric oven control circuit

The aged samples are then taken for the tensile test in the tensile machine whose elongation speed is $25 \mathrm{~mm} /$ min for flexible PVC and $5 \mathrm{~mm} / \mathrm{min}$ for rigid. 


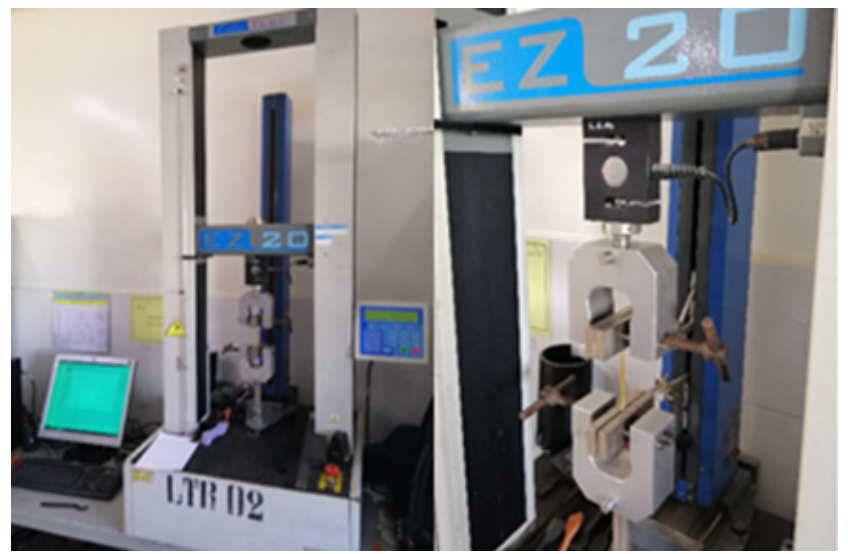

Figure 2: Machine tensile test

The results in Figure 3 show that the elongation of aged PVC decreased with a small difference in stiffness. These changes in mechanical characteristics are due to degradation caused by temperature and ultraviolet rays. [5]

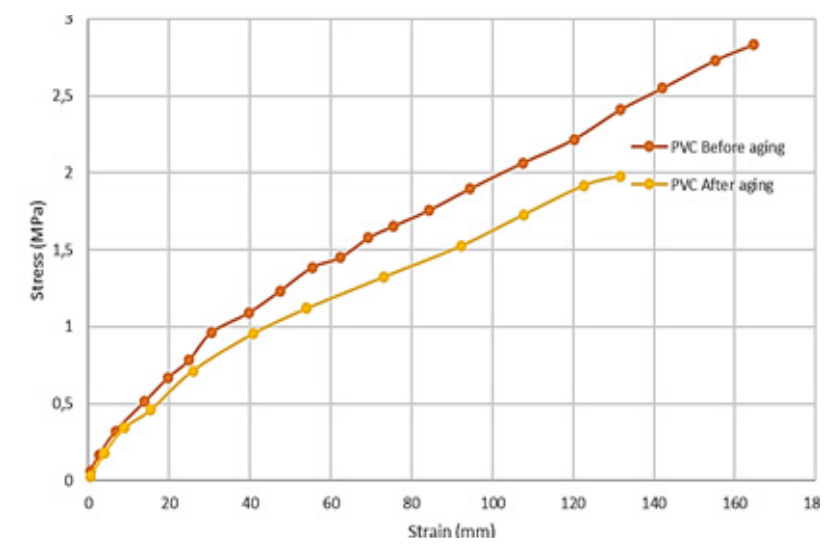

Figure 3: Tensile test of PVC before and after aging

After aging, the samples are ground in a mill as shown in figure 4 , then sifted in the form of powder as shown in figure 5 , then extruded in the form of a plate $2 \mathrm{~mm}$ thick. The specimens are forged from plates and then taken for a hardness test and a tensile test in the tensile machine as shown in figure 2 .

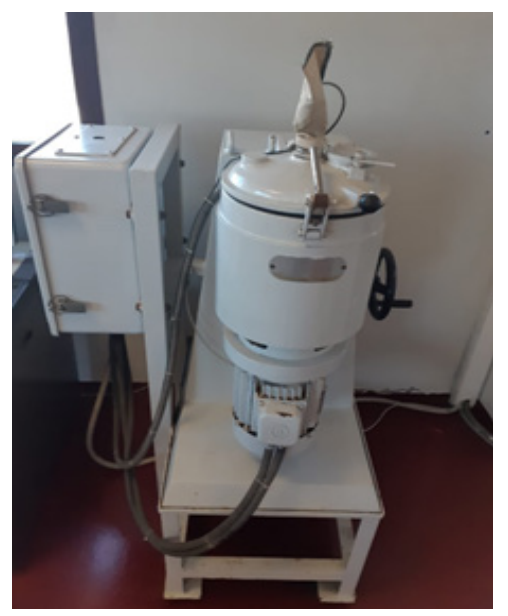

Figure 4: Crusher

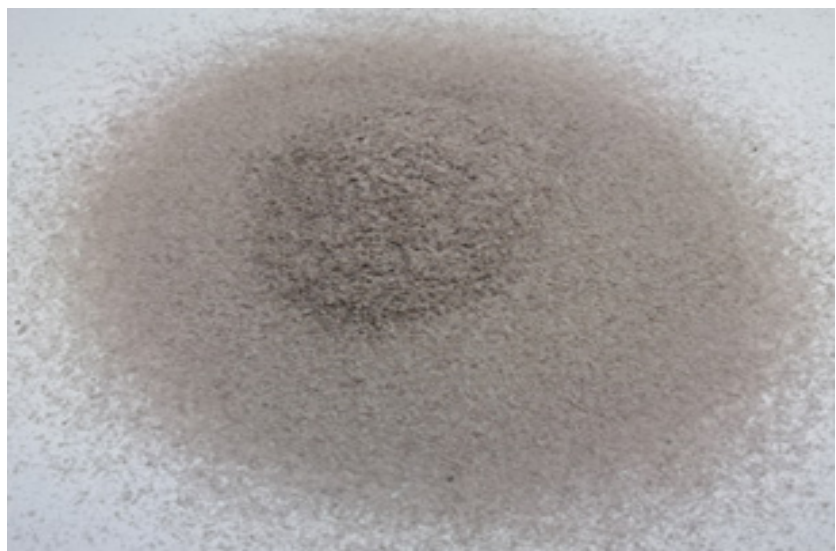

Figure 5: Sifted PVC powder

The effect of recycling on PVC is very clear as described in figure 6 . The material becomes more rigid with a strong reduction in elongation.

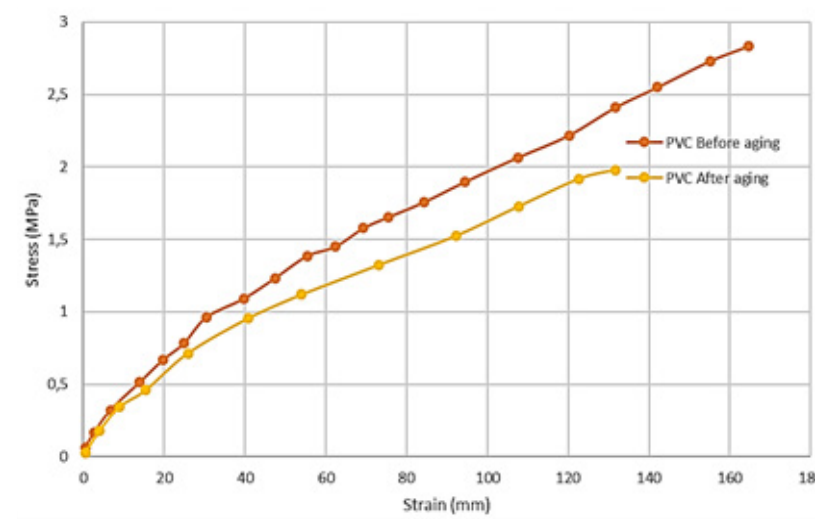

Figure 6: Tensile test of PVC before and after aging vs recycled one

Figures 3, 6 and Table 1 show the results obtained from the tensile tests carried out on the samples of PVC before and after aging and of the recycled one. These results clearly show the effect of aging which is negligible compared to that of recycling which is really remarkable in the level of change in stiffness as well as in the reduction in elongation. Elongation at break is reduced by more than $114 \mathrm{~mm}$, with an increase in tensile strength of $12.5 \mathrm{MPa}$, as a result PVC loses much of its flexibility and becomes more rigid.

Table 1: Stress and strain at break of PVC before and after aging and recycled

\begin{tabular}{|c|c|c|}
\hline & $\begin{array}{c}\text { Stress at break } \\
{[\mathrm{MPa}]}\end{array}$ & $\begin{array}{c}\text { Strain at break } \\
{[\mathrm{mm}]}\end{array}$ \\
\hline $\begin{array}{c}\text { Flexible PVC } \\
\text { before aging }\end{array}$ & 2,83 & 164,53 \\
\hline $\begin{array}{c}\text { Flexible PVC } \\
\text { after aging }\end{array}$ & 1,97 & 131,67 \\
\hline $\begin{array}{c}\text { Flexible PVC } \\
\text { recycled }\end{array}$ & 15,32 & 50,23 \\
\hline
\end{tabular}




\section{EFFECT OF BIO-LOAD ON RECYCLED PVC}

In Morocco as in other countries of the world, the consumption of red meat is increasing, leaving behind tons of waste. Among its waste are the horns (figure 7 below), which are thrown or incinerated in trash cans, with the exception of a small quantity intended for traditional crafts for the manufacture of key chains or decoration products. [8] to [11]

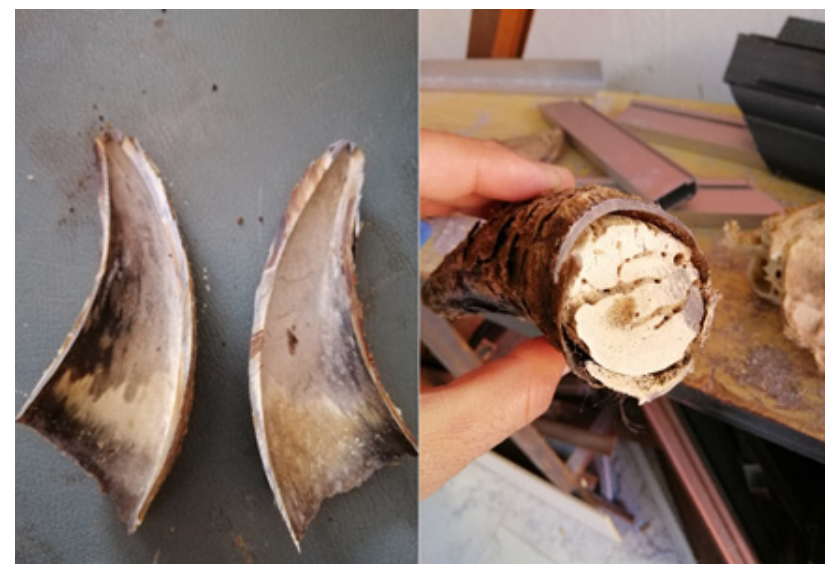

Figure 7: Cow horns

Also more than 490,000 tons of red meat consumed in Morocco, which implies a large quantity of horns lost or rather wasted in nature. Research engineers began to recycle horns by grinding them into objects through the sintering process. The horns cows are used here as a bio-load to improve the mechanical characteristics of recycled PVC. it is a rigid material as shown in figure 8 from a tensile test carried out on several specimens.

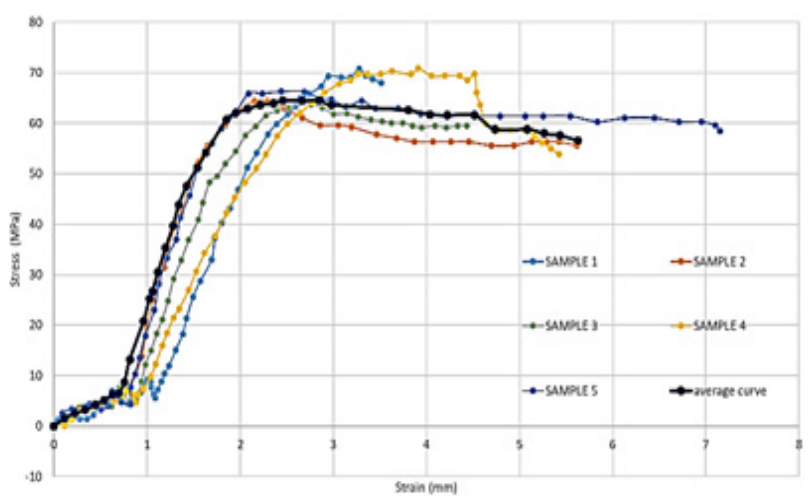

Figure 8: Tensile test for horns cow

Between 2004 and 2013, the total area devoted to coconut production rose from 11,1 million hectares to 12 million hectares. An adult coconut palm can hold between 50 and 500 coconuts, while coconut production increased by 13.5 per cent to 62 million tons in 2013 . [12] to [15] The coconut shell is used as a jar, but also finds industrial uses such as the manufacture of [6], the coconut shell powder is also used as a PVC load in the automotive sector. [7] In this study, the coconut shell is ground and then sifted as shown in figure 9 , to obtain a beam that will serve as a bio-load on the PVC to study its effect on the recyclability of this material.

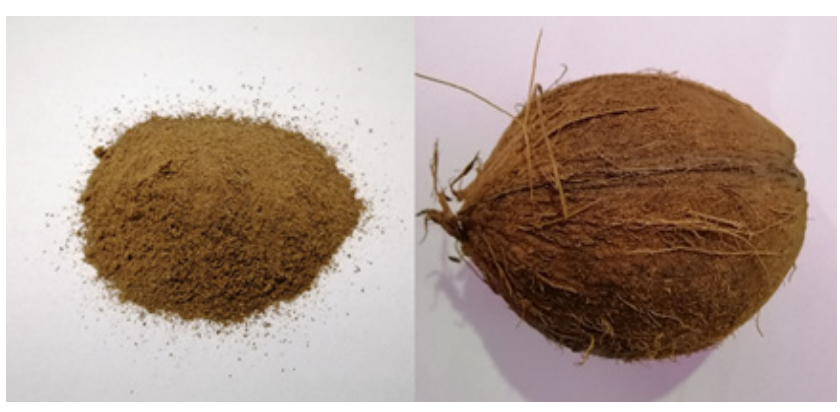

Figure 9: Coconut shell

There are 19 billion hens on Earth, two and a half times as many as human beings. Every year, 5 million tons of feathers are produced by the consumption of birds. These wastes are used in various ways in different areas usually as additives for composite materials. [16] to [22] as shown in figure 10 . Knowing that chicken feathers are made up of $98 \%$ keratin-a water-insoluble protein-the researchers have obtained a polymer made from a mixture of keratin-methyl acrylate. [20] The idea here is to use chicken feathers as a PVC bio-load to research its effect on the recyclability of the latter, as in the case of the other two bio-loads (cow horns and coconut).
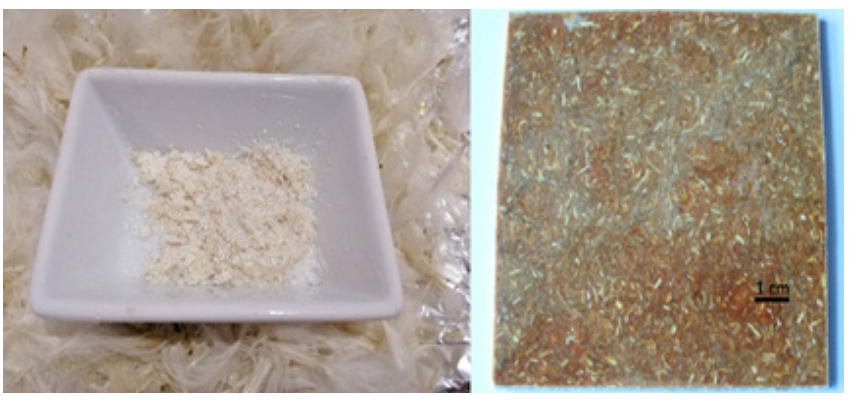

Figure 10: Chicken feathers [15]

The experiments are carried out according to the availability of the raw material aged between rigid PVC and flexible PVC. tensile tests are carried out on flexible PVC while hardness tests are carried out on rigid PVC. After aging in an oven with exposure to ultraviolet rays, the samples are then ground in a mill as shown in figure. 4, then sifted to obtain a powder as shown in figure. 5 . Then the quantity is divided into 4 portions, one part is used for recycling without additives, the other three parts We add bio-loads to it as additives, these bio-loads are cow horn, coconut and chicken feathers. The cow horns are first washed and then rubbed to remove the top layer, then put in the grinder to finally obtain a sifted powder as shown in figure 11. 


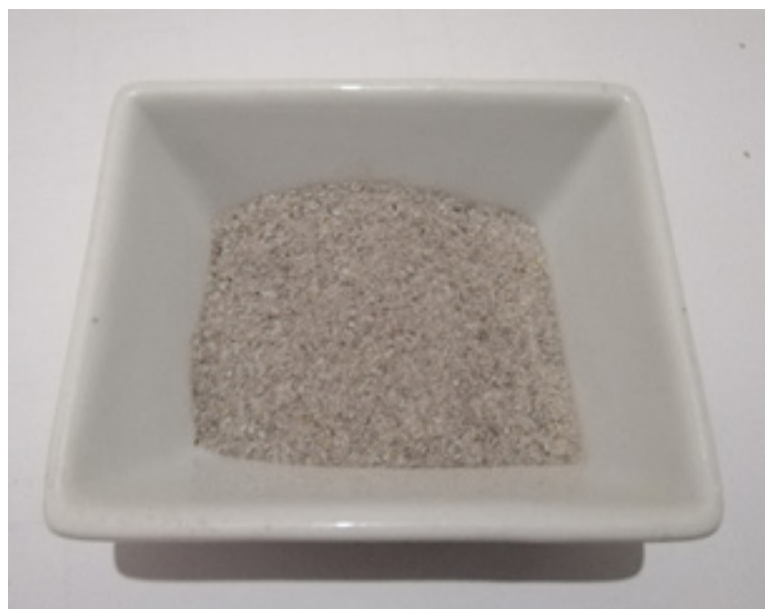

Figure 11: Cow horn powder

$10 \%$ of this bio-load has been added to the powder of the aged PVC, the mixture is then well ground to extrude plates $2 \mathrm{~mm}$ thick to take tensile specimens as shown in figure 12 below.

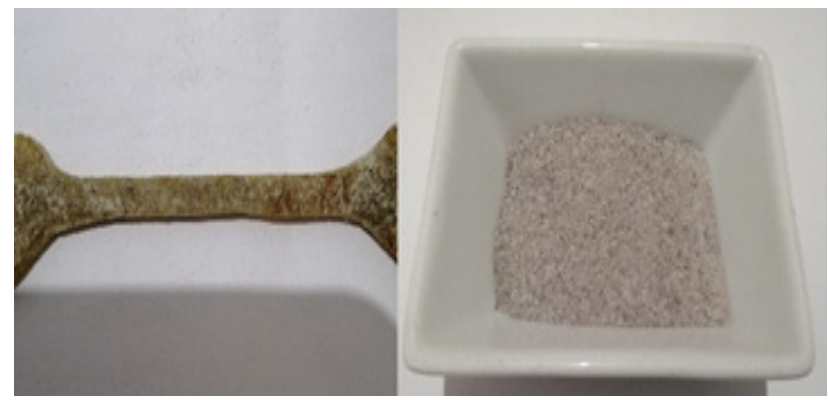

Figure 12: Mixture and tensile test specimen of PVC and cow horns

After piercing the coconut to remove the liquid, hitting the coconut with a hammer is still the easiest and most effective method of opening it. If the shot is done right, you don't even have to go very hard. Pieces of shell are obtained, using the same hammer they are broken so that it can be easily crushed, finally sifted to obtain a coconut powder. This approach is shown in the following figure.

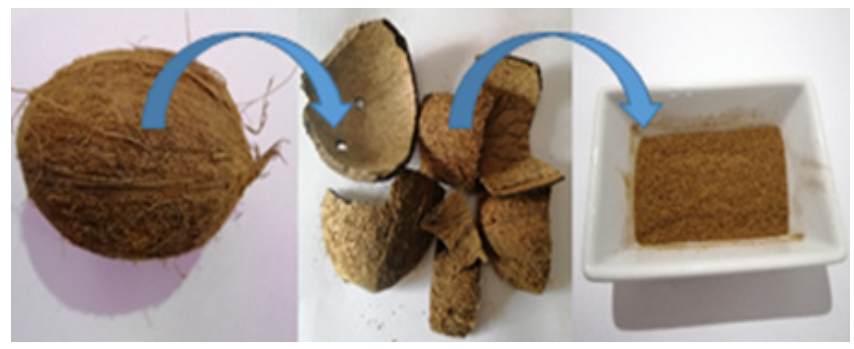

Figure 13: Coconut shell and powder

In the same way as what we did for cow horns, we take $10 \%$ of this coconut powder and add it to the aged PVC, we mix the whole and extrude thin sheets of thickness $2 \mathrm{~mm}$ through which samples are taken for tensile and hardness tests.

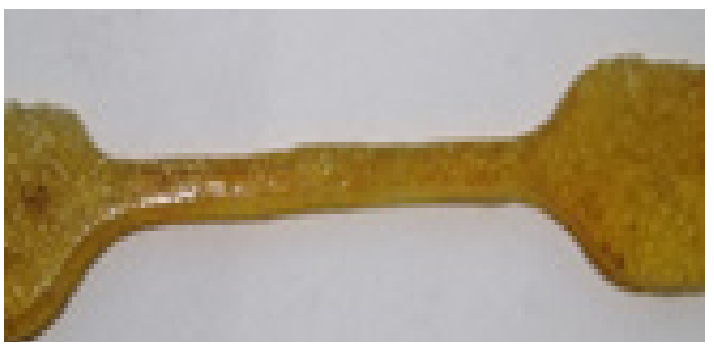

Figure 14: PVC \& coconut tensile test specimen

The feathers figure 15 are collected from a killing, then undergo several washes with tap water and a final wash with distilled water, after they are put in the oven for 15 min at a temperature of $423.15 \mathrm{~K}$, and finally crushed to take a powder of chicken feathers as shown in figure 15. [4]

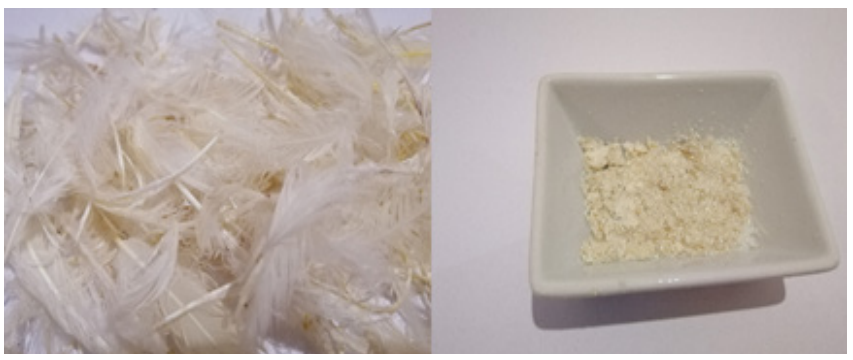

Figure 15: Chicken feathers \& powder

For chicken feathers, different percentages are mixed, $5 \%, 10 \%$ and $15 \%$. Each percent is crushed with aged PVC to achieve a homogeneous mixture through which 2 $\mathrm{mm}$ thick plates are extruded to take tensile specimens, as shown in Figure 16.

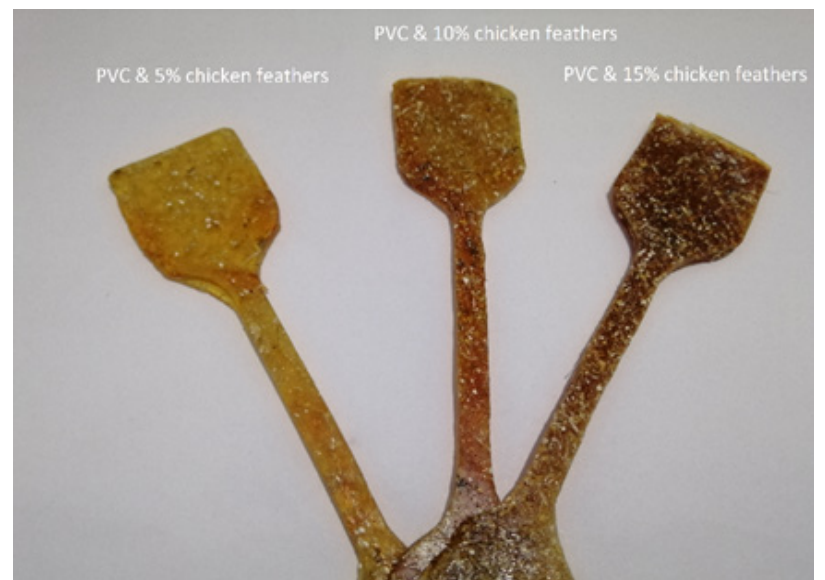

Figure 16: PVC \& chicken feathers tensile test specimen

After obtaining the test specimens using a punch having sharp edges and free of notches, the tensile test is carried out on the EZ20 tensile machine shown in figure 2 according to the standard: NF EN ISO 6259 and according to the following operating mode: 
1. Carry out the following procedure at a temperature of $296.15 \pm 2 \mathrm{~K}$

2. Measure the width and minimum thickness of the calibrated part of the specimen to the nearest $0.001 \mathrm{~mm}$, then calculated the air $A$ in the section

3. Draw two equidistant marks delimiting a length equal to $25 \mathrm{~mm} \pm 1 \mathrm{~mm}$ (mark with a pencil or ink so as not to affect the properties of the test piece)

4. Mount the specimen in the tensile machine

5. Make sure that the specimen is vertical

6. Tighten the jaws to prevent any slippage of the specimen

7. Set the test speed to $5 \mathrm{~mm} / \mathrm{min}$ for rigid PVC and $25 \mathrm{~mm} / \mathrm{min}$ for flexible PVC

8. Reset and start the machine

9. At the break of the specimen, note:

- $\quad$ The force at the yield point $F$

- $\quad$ The length between the marks after the break

Raise from curves

- $\quad$ The stress at the yield point

$$
\sigma=\frac{F}{A}
$$

- Elongation at rupture

$$
\varepsilon=\frac{L-L 0}{L 0}
$$

LO: initial distance between the two marks: $25 \mathrm{~mm} \mathrm{~L}$ : distance between the two benchmarks after the breakThe tests are carried out first of all on five test pieces of cow horns to obtain the mechanical characteristics of this bioload from an average curve which is deduced from the other curves as shown in figure 17.

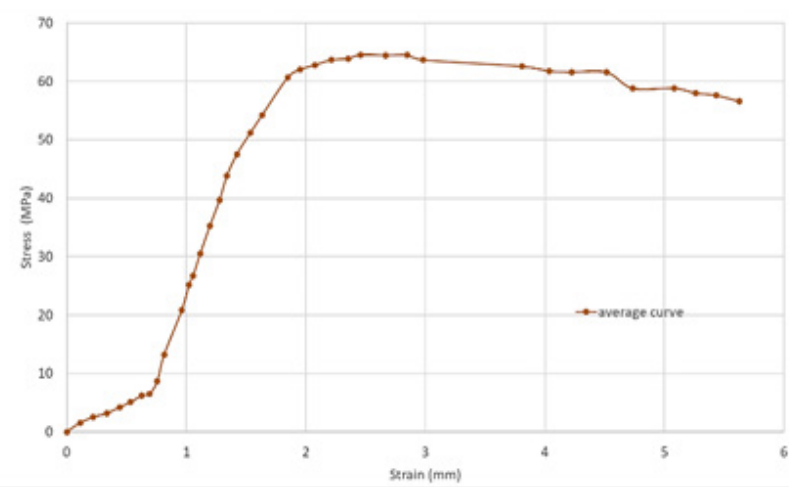

Figure 17: Average curve for Tensile test cow horns

The test of the determination of the softening temperature (Vicat) consists in determining the temperature at which the mechanical strength of a thermoplastic material becomes insufficient.
The elements of the test: (figure 18)

- A hardened steel indenter tip, $3 \mathrm{~mm}$ long and with a circular section of area $1 \mathrm{~mm} \pm$ $0.015 \mathrm{~mm} 2$

- A gimbal micrometer calibrated to measure within $0.01 \mathrm{~mm}$ the penetration of the tip of the indenter into the specimen

- A weight plate attached to the rod and suitable weights such that the total thrust applied to the test piece can be adjusted to method A50: load $50 \mathrm{~N}$ and heating rate $323.15 \mathrm{~K} / \mathrm{H}$

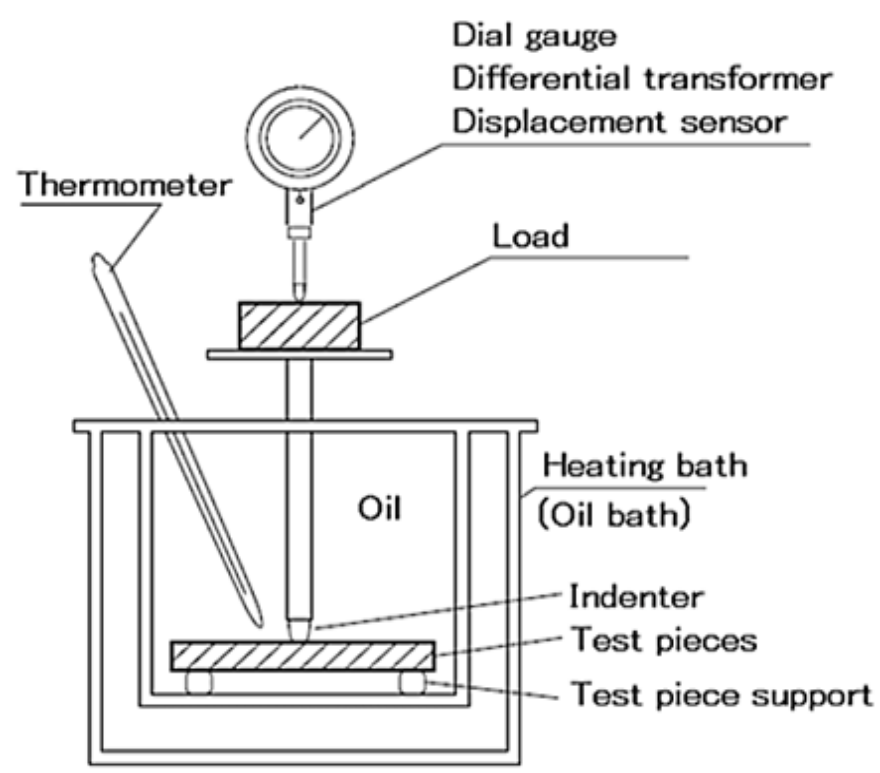

Figure 18: Schematic diagram to determine the softening temperature

This test is carried out on rigid PVC reinforced with two rigid bio-loads, cow horns and coconut, and on recycled PVC without additives. In this test we do not seek to obtain the softening temperature but to carry out a comparative study to find the most resistant material since the test machine is not connected to a central unit to record the curves. The idea is to place the three samples under the indenters, following the procedure below. If the indenter reaches $1 \mathrm{~mm}$ deep before the temperature reaches $353.15 \mathrm{~K}$, the material is said to meet the standards. What can be seen in Figure 19 is that when the temperature reaches $353.15 \mathrm{~K}$ the comparators display the penetration results, the one which is the most penetrated is the least resistant. First, the specimen must be conditioned for $5 \mathrm{~min}$ at a temperature of at least 323.15 $\mathrm{K}$ at the assumed softening temperature. then follow the following operating mode:

- $\quad$ Bring the heating bath to a temperature below 323.15 $\mathrm{K}$, maintain this temperature constant. 
- Place the specimen on its concave face horizontally under the tip of the penetrator of the unloaded rod

- Lower the assembly into the oil bath

- After 5 min apply the 4 additional weights on the load carrier

- Set the comparator (micrometer) to zero

- Press test to start the test

- When the micrometer indicates a penetration of $1 \mathrm{~mm}( \pm 0.01)$ in the specimen, the value of the softening temperature is transmitted to the printer

- The bath must be allowed to cool before starting a new test

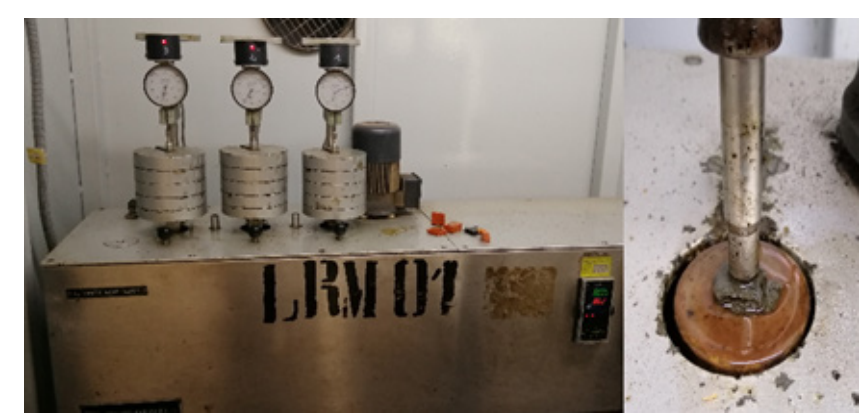

Figure 19: Vicat testing machine

The sample of recycled PVC without additives is under penetrator 1. The sample of PVC + coconut is under penetrator 2. The sample of PVC + cow horns is under penetrator 3 .

\section{RESULTS AND DISCUSSION}

The tensile test on the PVC specimen reinforced with $10 \%$ cow horn powder is carried out on the tensile machine shown in figure 2 . The flexible PVC becomes more rigid.

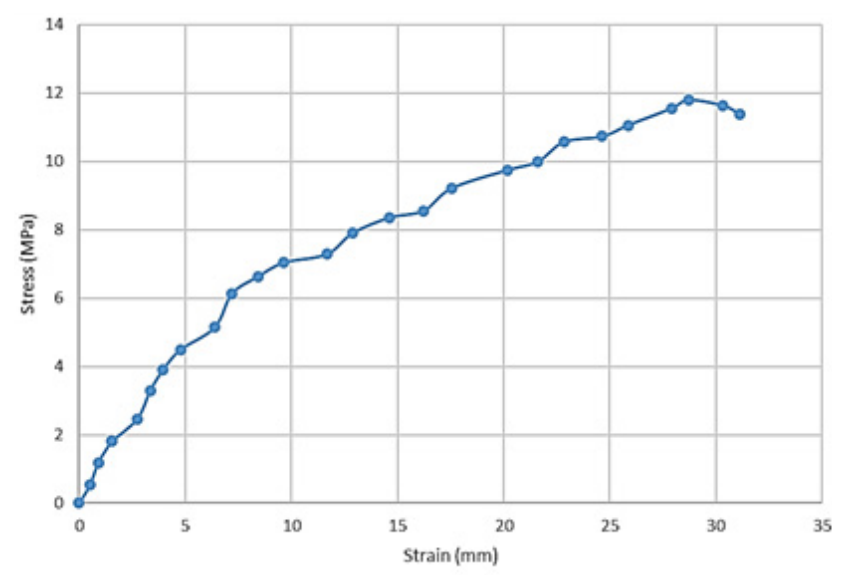

Figure 20: Tensile test of bio-loaded PVC by $10 \%$ of cow horns
The result of the test on the flexible test specimen in PVC reinforced with coconut as bio-load as described in figure 20 , was not far from that reinforced by cow horns since the two materials are rigid.

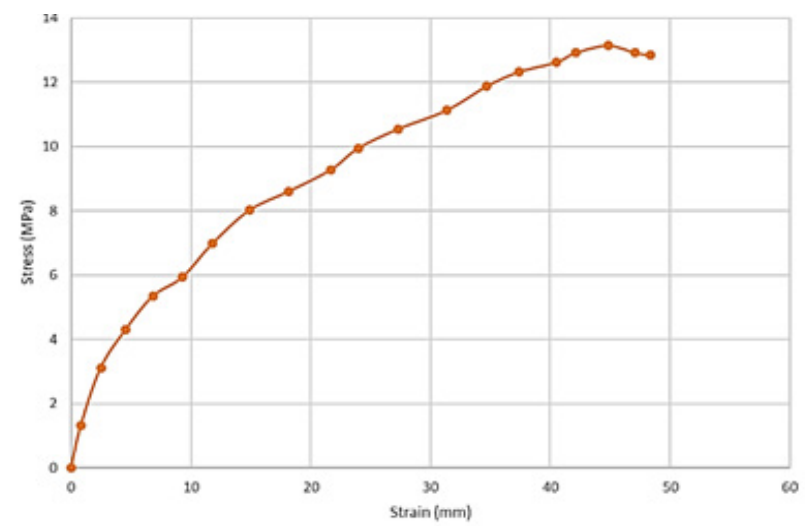

Figure 21: Tensile test of bio-loaded PVC by $10 \%$ of coconut

For the reinforcement of flexible PVC by chicken feathers, the experiments are made on the addition of three percentages, 5,10 , and $15 \%$, of which the $10 \%$ is the best quantity to improve the mechanical characteristics of PVC, while minimizing the deterioration of its flexibility. Figure 21 shows the tensile result on the PVC specimen reinforced with $10 \%$ chicken feather powder.

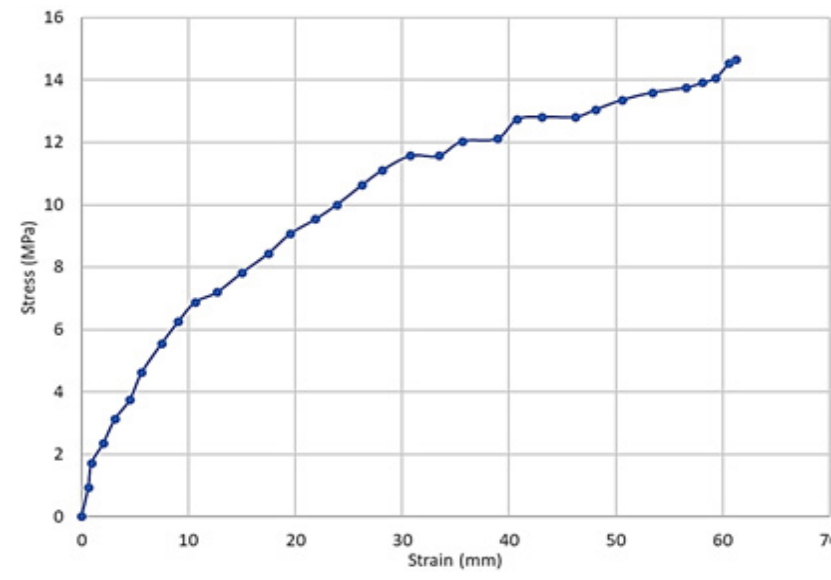

Figure 22: Tensile test of bio-loaded PVC by $10 \%$ chicken feathers

The experimental study is a comparison of the addition of the three types of bio-loads on flexible PVC to find which between them is able to improve the mechanical characteristics of recycled PVC without additives. The results of each test are gathered on the same graph in figure 22, and in table 2, to compare the effect of each bio-loads on flexible PVC. 


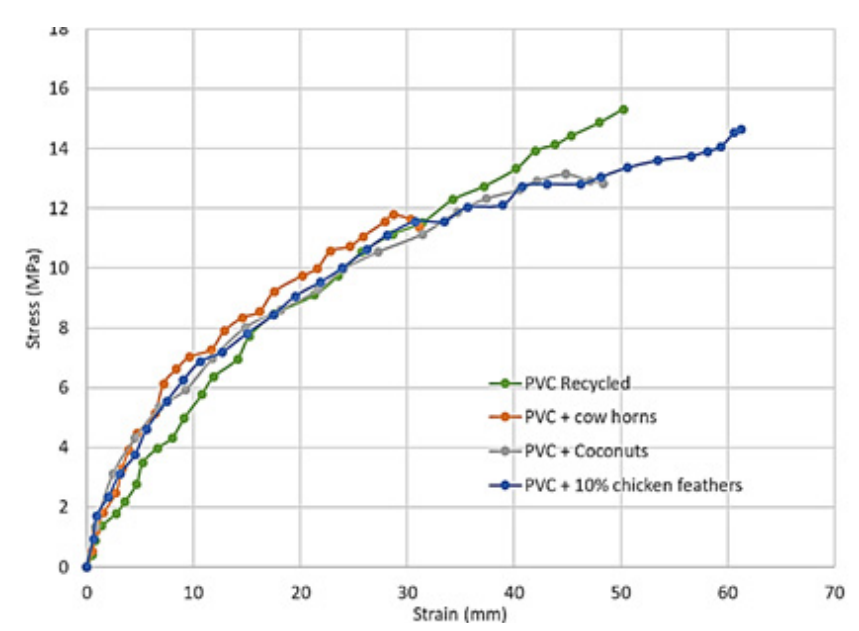

Figure 23: Tensile curves of flexible PVC reinforced by the three bio-loads

Table 2: Stress and strain at break of flexible PVC with/ without bio-loads

\begin{tabular}{|c|c|c|}
\hline & $\begin{array}{c}\text { Stress at break } \\
{[\mathrm{MPa}]}\end{array}$ & $\begin{array}{c}\text { Strain at break } \\
{[\mathrm{mm}]}\end{array}$ \\
\hline $\begin{array}{c}\text { Flexible PVC } \\
\text { recycled without } \\
\text { bio-loads }\end{array}$ & 15,32 & 50,23 \\
\hline $\begin{array}{c}\text { Flexible PVC } \\
\text { bio-loaded with } \\
10 \% \text { of cow } \\
\text { horns }\end{array}$ & 11,37 & 31,14 \\
\hline $\begin{array}{c}\text { Flexible PVC } \\
\text { bio-loaded with } \\
10 \% \text { of coconut }\end{array}$ & 12,84 & 48,35 \\
\hline $\begin{array}{c}\text { Flexible PVC } \\
\text { bio-loaded with } \\
10 \% \text { of chicken } \\
\text { feathers }\end{array}$ & 14,65 & 61,25 \\
\hline
\end{tabular}

In terms of rigidity, it is clear that the PVC reinforced by the coconut is a little more rigid than that reinforced by the cow horns, this is what is shown in figure 23. When the temperature reaches $353.15 \mathrm{~K}$ the penetrator depth values are summarized in table 3 .

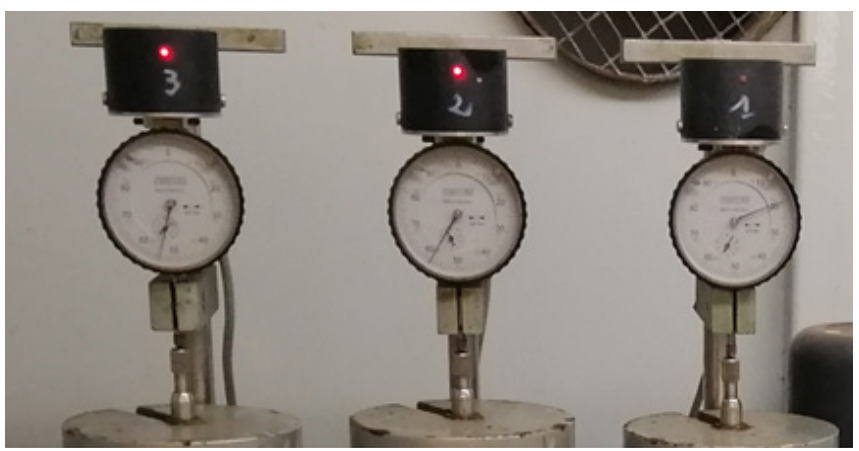

Figure 24: Penetration depth
Table 3: Penetration depth at $353.15 \mathrm{~K}$

\begin{tabular}{|c|c|}
\hline & $\begin{array}{c}\text { Penetration depth at } \\
353.15 \mathrm{~K} \\
{[\mathrm{~mm}]}\end{array}$ \\
\hline $\begin{array}{c}\text { Rigid PVC recycled } \\
\text { without bio-loads }\end{array}$ & 0,8 \\
\hline $\begin{array}{c}\text { Rigid PVC bio-loaded } \\
\text { with 10\% of coconut }\end{array}$ & 0,42 \\
\hline $\begin{array}{c}\text { Rigid PVC bio-loaded } \\
\text { with 10\% of cow horns }\end{array}$ & 0,46 \\
\hline
\end{tabular}

The results clearly show that the effect of chicken feathers is the most efficient bio-load for improving the mechanical characteristics of recycled PVC. In Tables 2 and 3 as well as in Figure 23, and by a simple comparison of the values obtained, a large difference is obtained in the elongation at break. The only bio-load that improved the performance of recycled PVC was chicken feathers, while the values of other bio-loads were close to that recycled without additives. In terms of rigidity, the reinforcement of the PVC by chicken feathers has a little reduced the stress at break which reduces the rigidity. Then finally we can deduce that the chicken feathers as a bio-load to improve the flexibility and the rigidity of the recycled PVC material.

\section{COST ANALYSIS}

Any waste that can undergo natural biological, anaerobic or aerobic decomposition, such as food waste, garden waste, paper and cardboard waste, as well as animal corpses, is biodegradable waste. [26] In this article, we have used three bio-loads which are cow horns, coconut, and chicken feathers. In this cost study, the coconut is neglected for several reasons, the first is the availability in Morocco, the coconut is imported for uses which remain modest until now compared to other countries, the second if we want to harvest it, we have to buy it waste. For example, the purchase of a ton of coconut waste costs 30 euros [27], not counting transport costs. While the other two bio-loads are available throughout the kingdom. Slaughterhouses in Morocco are not yet equipped with recovery systems for slaughter by-products with a view to possible recovery, [28] this is why we are talking about the availability of these two bio-loads at country level, its will just be collected for free from the slaughterhouses. The data for a cost study of these two types of bio-loads being scarce, and to gather information on the collection costs of these two wastes and the cost of treatment before grinding, we consulted a company specializing in waste management industrial, and some craftsmen in Morocco known for making traditional products using biodegradable materials such as cow hides and horns. These two sources of information give us estimates on the cost of collecting and treating the 
two bio-loads just before their grinding. this information is summarized in table 4 below

Table 3: Cost of bio-loaded waste collection and treatment operations

\begin{tabular}{|c|c|c|}
\hline & \multicolumn{2}{|c|}{ Cost/Kg [Euro] } \\
\hline Bio-load & Cow horn & Cow horn \\
\hline $\begin{array}{c}\text { Collecting \& } \\
\text { sorting }\end{array}$ & 0.095 & 0.095 \\
\hline Treatment & 0.2 & 0.2 \\
\hline Total & 0.295 & 0.295 \\
\hline
\end{tabular}

The transport operation is neglected since there is at least one slaughterhouse in each city, so the bio-load is available in each city. The treatment of cow horns consists of separating the horns from the cow's skull by a shearing operation, while the treatment on the feathers of chickens requires several operations starting with sorting the feathers from the rest of the chicken waste, intestines, legs and heads, then washing the feathers several times finally drying in an oven. In this cost study we notice a small variation between the cost of feathers waste compared to that of cow horns waste, this due to feathers processing operations, but the availability of feathers as waste is greater compared to that of cow horns.

\section{CONCLUSION}

Recycling cardboard boxes prevents thousands of trees from being cut down every year. Recycling glass saves sand. Recycling plastic reduces oil consumption. The recycling of aluminum reduces the extraction of the boxite. Recycling also involves the degradation of the recycled material. But also save tons of materials that just went into the trash, and it will be better if we recycle these materials with bio-loads that are available everywhere and just wasted in nature. The contribution of this article to scientific research lies in the search for a bio-load to be added to recycled PVC to improve their mechanical characteristics. The study is carried out experimentally on three bio-loads of which the chicken feathers are the best of them. the other two bio-loads (cow horns and coconut) decrease elongation at break and also increase rigidity. Adding $10 \%$ chicken feathers to the recycled PVC improves flexibility by recovering elongation length at break, and stiffness by reducing stress at break. for these recoverable values, we will be sure to increase the recyclability number of PVC. A future study will be carried out by neural networks to predict the mechanical behavior of the PVC matrix with different percentages of different bio-loads, to finally find a competitive material compared to those on the industrial market.

\section{REFERENCES}

1. Lakhdar, A., Moumen, A., Zahiri, L., Jammoukh, M., Mansouri, K. (2020). Experimental and Numerical Study of the Mechanical Behavior of Bio-Loaded PVC Subjected to Aging. Adv. Sci. Technol. Eng. Syst. J. 5(5), 607-612, DOI: 10.25046/aj050574

2. Moumen, A., Jammoukh, M.» Zahiri, L., Mansouri, K. (2020).ґ Study Of The Optimal Micromechanical Behavior Of A Polymer Reinforced By Snail Shell Particles Using The Mori-Tanaka Numerical Model. IEEE International conference of Moroccan Geomatics (Morgeo), 1-6, 2020, doi:10.1109/Morgeo49228.2020.9121908

3. Janajreh, I., Alshrah, M., Zamzam, S. (2015). Mechanical recycling of PVC plasticwaste streams from cable industry: A case study. Sustainable Cities and Society, 18, 13-20.

4. DJEBBAR, S., YOUSSFI, B. (2014) .contribution to the enhancement of poultry feathers as an element of fungal fermentation. microbiology department, constantine university, 53.

5. Lakhdar, A., Zahiri, L., Jammoukh, M., Moumen, A., Mansouri, K., Salhi, B. (2020).ґ Numerical and Experimental Study of the Behavior of PVC Material Subjected to Aging. 1st International Conference on Innovative Research in Applied Science, Engineering and Technology (IRASET), IEEE: 1-6.

6. Coconut, UNITED NATIONS CONFERENCE ON TRADE AND DEVELOPMENT, INFOCOMM, New York and Geneva, 2016 p12

7. Hanafi, M. (2017). Mechanical Properties of Coconut Shell Powder Reinforced PVC Composites in Automotive Applications. Journal of Mechanical Engineering. 14. 49-61.

8. Moumen, A., Jammoukh, M. ¡Zahiri, L., Mansouri, K. (2020). Numerical modeling of the thermo mechanical behavior of a polymer reinforced by horn fibers. International Journal of Advanced Trends in Computer Science and Engineering, 9(4), 6541-6548, doi:10.30534/ijatcse/2020/342942020

9. Nemat, S., Hori, M. (1993). Micromechanics: overall properties of heterogeneous materials.

10. V Titow, W. (1984). Stabilisers: general aspects. Springer: 255-333.

11. Jammoukh, M., Mansouri, K., Salhi, B. (2018). Industrial and ecological effect of a bio-load on polymers. $10 p$.

12. Fonds de la CNUCED pour l'information sur les marchés des produits de base agricoles. (2016). Noix de coco, Un profil de produit de base par INFOCOMM. CONFERENCE DES NATIONS UNIES SUR LE COMMERCE ET LE DEVELOPPEMENT, $\mathrm{p} 12$, New York et Genève. 
13. Coralie, B., Audrey, S. (2011). Aspects botaniques, applications et perspectives thérapeutiques de cocos nucifera L. Université de Nantes.

14. Raghavendra, S.N., Ramachandra, S.R., Swamy., Rastogi, N.K., Raghavarao, K.S.M.S., Kumar, S., Tharanathan, R.N. (2006) Grinding characteristics and hydration properties of coconut residue: $A$ source of dietary fiber. Journal of Food Engineering, Volume 72, Issue 3, Pages 281-286, https://doi. org/10.1016/j.jfoodeng.2004.12.008

15. Lomelí-Ramírez, M., Kestur, S., Manríquez-González, R., Iwakiri, S., Bolzon de Muniz, ., Flores-Sahagun, T.(2014). Bio-composites of cassava starch-green coconut fiber: Part II-Structure and properties. Carbohydrate Polymers,Volume102,576583,https://doi. org/10.1016/j.carbpol.2013.11.020.

16. Aranberri , I., Montes ID , S., Azcune, I., Rekondo, A., Grande, H. (2017) .Fully Biodegradable Biocomposites with High Chicken Feather Content. CIDETEC Research Centre, Paseo de Miramón, 196, 20014 Donostia-San Sebastián (Gipuzkoa), Spain, Polymers, 9, 593

17. Ansarullah., Rahim, R., Kusno, A., Baharuddin., Jamala, N. (2018). Utilization of waste of chicken feathers and waste of cardboard as the material of acoustic panel maker. IOP Conf. Ser.: Earth Environ. Sci. 126012036.

18. Schmidt, W.F. (1998). Innovative Feather Utilization Strategies. in Poultry Waste Management Conference, Springdale, Arkansas.

19. Mohanty, AK., Misra, M., Drzal, LT.(2002). Sustainable biocomposites from renewable resources: opportunities and challenges in the green materials world. J Polym Environ,10(1-2):19-26.

20. Narendra Reddy ÆE Yiqi Yang. (2007). Structure and Properties of Chicken Feather Barbs as Natural Protein Fibers. Springer Science+Business Media, LLC 2007, J Polym Environ 15:81-87, DOI 10.1007/ s10924-007-0054-7
21. Dash, A., Tripathy, S. (2018) .Mechanical characteristics of chicken feather teak wood dust epoxy filled composite. International Conference on Mechanical, Materials and Renewable Energy, IOP Conf. Series: Materials Science and Engineering 377, 012111, doi:10.1088/1757-899X/377/1/012111.

22. Fonds de la CNUCED pour l'information sur les marchés des produits de base agricoles. (2016). Noix de coco, Un profil de produit de base par INFOCOMM. CONFERENCE DES NATIONS UNIES SUR LE COMMERCE ET LE DEVELOPPEMENT, p12, New York et Genève.

23. C.D.E.S. Activités, L. De Vinylplus. (2020). PROGRESS REPORT 2020 REPORTING ON 2019 ACTIVITIES. 2017. 40:7-12.

24. Lakhdar, A., Moumen, A., Mansouri, K.|(2021). Study Of The Mechanical Behavior Of Bio Loaded Flexible Pvc By Coconut And Horn Fibers Subjected To Aging. International Journal on Technical and Physical Problems of Engineering (IJTPE), Iss. 46, Vol. 13, No. 11."

25. Lakhdar, A., Moumen, A.,'Mansouri, K.| (2021). Recycled PVC with chicken feathers as bio-load. IOP Conference Series Materials Science and Engineering, India."

26. Dahir $n^{\circ}$ 1-06-153, 30 Chaoual 1427 (2006). Law No. 28-00 on waste management and disposal. Morocco, BO $n^{\circ} 5480$.

27. ECOFIND, Analyse de la maturité. Les fibres naturelles à partir de déchets de coco, from www.recube.frDécouvrezenplussurEcofindici:https://vimeo. com/173891553, accessed on 2021-01-10.

28. CHENNAOUI, M., FARID, F., HAMDANI, A., MOUNTADAR, M., ASSOBHEI, O. (2012). Biotransformation des déchets d'abattoir en vue de leur valorisation dans đ'alimentation animale. DÉCHETS SCIENCES \& TECHNIQUES - REVUE FRANCOPHONE D'ÉCOLOGIE INDUSTRIELLE - N61. 